\title{
Postoperative outcomes after preoperative ustekinumab exposure in patients with Crohn's disease: a systematic review and meta-analysis
}

\author{
Rajat Garga , Babu P. Mohan' ${ }^{b}$ Suresh Ponnadac, Miguel Regueirod, Amy L. Lightnere, Benjamin Click \\ Cleveland Clinic Foundation, Cleveland; Banner University Medical Center/University of Arizona, Tucson; Carilion \\ Roanoke Medical Center, Roanoke, Virginia, USA
}

Abstract

${ }^{a}$ Department of Internal Medicine, Cleveland Clinic Foundation, Cleveland (Rajat Garg); ${ }^{b}$ Department of Internal Medicine, Banner University Medical Center/University of Arizona, Tucson, Arizona (Babu P. Mohan); 'Department of Internal Medicine, Carilion Roanoke Medical Center, Roanoke, Virginia (Suresh Ponnada); ${ }^{\mathrm{d} D e p a r t m e n t ~ o f ~ G a s t r o e n t e r o l o g y ~}$ and Hepatology, Cleveland Clinic Foundation, Cleveland, Ohio (Miguel Regueiro, Benjamin Click); ${ }^{\mathrm{e}}$ Department of Colorectal Surgery, Cleveland Clinic Foundation, Cleveland, Ohio (Amy L. Lightner), USA

Conflict of Interest: Miguel Regueiro: Research support from AbbVie, Janssen, Takeda, Pfizer Unrestricted Educational Grants from AbbVie, Janssen, UCB, Pfizer, Takeda, Salix, Shire Advisory Boards and Consultant for AbbVie, Janssen, UCB, Takeda, Pfizer, Miraca Labs, Amgen, Celgene, Seres, Allergan, Genentech, Gilead, Salix, and Prometheus.

Amy L. Lightner: Takeda, consultant. Benjamin Click: Consultant for Takeda and TARGET PharmaSolutions along with speakers' bureau for Takeda

Correspondence to: Rajat Garg, MD, Department of Hospital Medicine, 9500 Euclid Avenue, Cleveland Clinic Foundation, Cleveland, OH, 44195 USA, e-mail: drgargrajat@gmail.com

Received 26 November 2020; accepted 24 February 2021; published online 3 June 2021

DOI: https://doi.org/10.20524/aog.2021.0634

\section{Introduction}

Crohn's disease $(\mathrm{CD})$ is chronic inflammatory condition affecting the gastrointestinal tract $[1,2]$. There has been significant expansion of medical therapy in last 3 decades following the initial approval of tumor necrosis factor (TNF) inhibitors in $1998[3,4]$. There are now multiple monoclonal antibody mechanisms approved for $\mathrm{CD}$, including TNF inhibitors (infliximab, adalimumab, certolizumab pegol), integrin inhibitors (natalizumab, vedolizumab), and an interleukin 12/23 inhibitor, ustekinumab (UST). UST has shown good efficacy and safety similar to anti-TNF agents and vedolizumab in the treatment of $\mathrm{CD}$ [5-8].

Despite the availability of multiple medical therapies, as many as $75 \%$ of $\mathrm{CD}$ patients will undergo major abdominal surgery in their lifetime [9]. Furthermore, approximately $30-50 \%$ of patients are on biologic therapy at the time of surgery [10]. There has been much interest in the impact of biologic medications on postoperative outcomes, given the theoretical risks of immune modulation throughout the perioperative period. Initially anti-TNFs were thought 
to increase the risk of anastomotic leaks, but later studies refuted these findings and the literature remains controversial $[11,12]$. Subsequently, retrospective studies assessing the impact of vedolizumab on postoperative outcomes suggested vedolizumab exposure was also a potential risk factor for adverse postoperative outcomes; however, further data has contradicted these early findings [13-15].

Most recently, studies have reported conflicting data on the risk of postoperative complications in patients receiving UST for CD [16-18]. Therefore, we performed a systematic review and meta-analysis to better assess and quantify the risk of postoperative complications in CD patients exposed to UST prior to abdomino-pelvic surgery.

\section{Materials and methods}

\section{Search strategy}

A comprehensive search of multiple databases was conducted from inception to October 2020. These databases were Ovid MEDLINE ${ }^{\circledast}$, Scopus, Embase, Cochrane Central Register of Controlled trials, and Cochrane Database of Systematic Reviews. The keywords used were: "ustekinumab", "complications", "postoperative”, “infections", "crohn's disease”. The MOOSE checklist was followed and is provided in Supplementary Table $1[19,20]$.

\section{Study selection}

In this meta-analysis, we included studies that evaluated postoperative complications in the setting of preoperative UST exposure in adult patients. We included studies irrespective of the sample size, geography and clinical setting, as long as data were provided for analysis.

Our exclusion criteria were pediatric population (age $<18$ years), and studies published in a language other than English.

\section{Data abstraction and quality assessment}

All data from individual studies on outcomes were abstracted on a standardized form by 2 authors (RG, ALL). In addition, 2 authors (RG, BPM) did the quality scoring independently. We contacted primary study authors via email for further information or clarification of data if needed.

In the case of data from the same author or institution(s), we contacted the study authors to ascertain the potential for data duplication. If overlap existed, we included overlapping studies if there were differences in outcomes or data reported. To limit potential bias and assess the influence of this approach, we excluded overlapping outcomes when possible, and performed sensitivity analyses excluding the potentially overlapping data.
We used the Newcastle-Ottawa scale for cohort studies to assess the quality of studies [21]. It consists of 8 questions; details are provided in Supplementary Table 2.

\section{Outcomes}

The following outcomes and definitions were included in CD patients who underwent abdomino-pelvic surgery with preoperative UST use: pooled rates of any postoperative complication, any infectious complication, intra-abdominal sepsis, readmission, and reoperation. The term "infectious complication" comprised any infections, including surgical site infections, urinary tract infections or non-surgical site infections such as pneumonia. The definition was consistent across all studies. Because of study variability and limited data, further subgrouping of infectious complications was not possible. Intra-abdominal sepsis was defined as the combination of anastomotic leak and intra-abdominal abscess, as previously reported [16]. For studies that reported comparator populations, these were included in the subgroup analysis if at least 3 studies presented similar comparison groups. All definitions were assigned by individual study authors.

\section{Other data variables}

We extracted baseline data on study type, last dose of drug prior to surgery, sex, age, tobacco use and preoperative steroid use. In addition, procedural data including ostomy creation and type of procedure, either laparoscopic or open, were also collected. All the data abstracted are shown in Tables 1 and 2 as population characteristics.

\section{Statistical analysis}

Meta-analysis techniques were used to calculate the pooled estimates for each outcome, using the logit transformed proportion and random-effects model suggested by DerSimonian and Laird [22]. A continuity correction of 0.5 was added if the incidence of an outcome was zero before statistical analysis [23]. Heterogeneity was assessed between study-specific estimates using the Cochran Q statistical test for heterogeneity and the $I^{2}$ statistics along with 95\% confidence intervals (CI) $[24,25]$. The $I^{2}$ value signifies what proportion of the dispersion is true vs. chance [26]: low, moderate, substantial, and considerable heterogeneity were suggested by values of $<30 \%, 30-60 \%, 61-75 \%$, and $>75 \%$, respectively [27]. Publication bias was ascertained qualitatively, by visual inspection of funnel plots, and quantitatively, by the Egger test [28]. A $P$ value of $<0.05$ was used to define statistically significant difference. For outcomes and variables of interest, further metaregression analyses were also performed to identify predictors. The choice of variables was based on data availability and all variables were considered for inclusion. Subgroup analysis was 


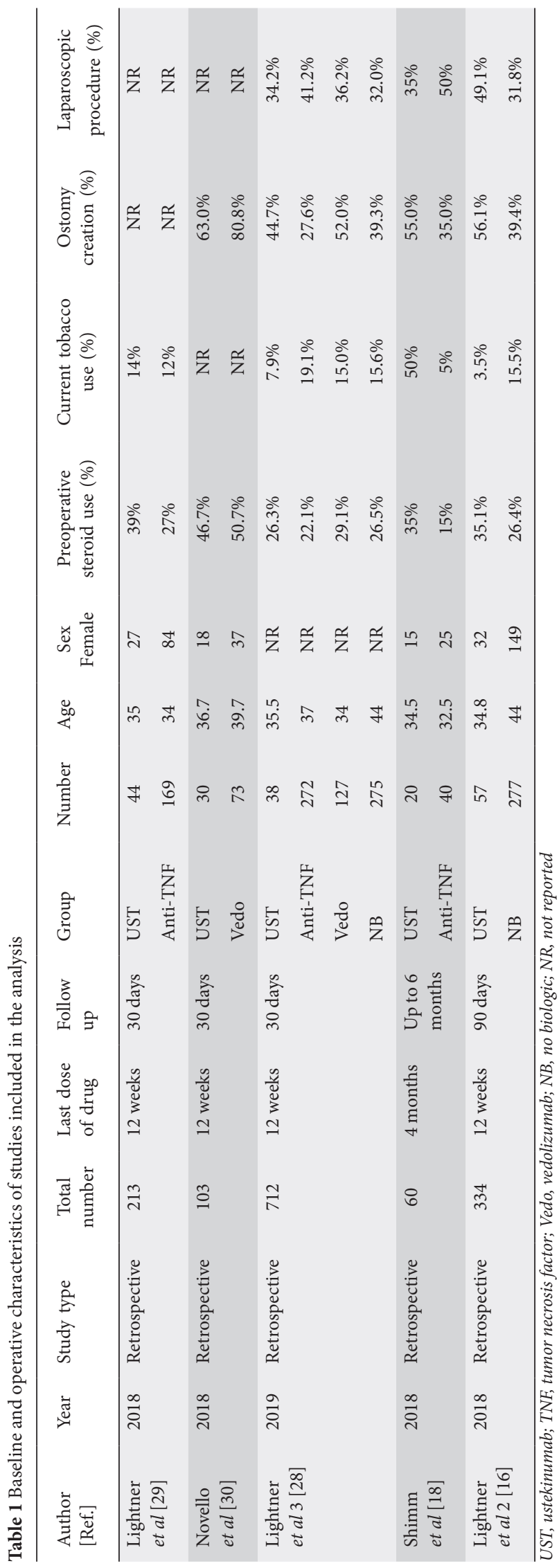

performed if the outcome of interest and the variables were reported in at least 3 studies. Comprehensive Meta-Analysis (CMA) software, version 3 (BioStat, Englewood, NJ) was used to perform all analysis.

\section{Results}

\section{Search results and population characteristics}

The initial search resulted in 94 studies. Sixty records were screened after removing duplicates and 11 full-length articles were assessed after initial screening. Six studies were excluded as the outcome of interest was not present, leaving 5 studies in the final analysis that reported postoperative outcomes in CD patients with preoperative UST use [16,18,29-31]. Fig. 1 shows the schematic diagram of study selection.

A total of 1422 patients were included; 189 (13.2\%) received preoperative UST, 481 (33.8\%) anti-TNF, 200 (14.0\%) vedolizumab, and $552(38.8 \%)$ no biologics. Sex was reported in 4 studies in the UST group and the majority of patients were female $(61 \%)$. The median age was 35 years, with a general age range of 34.5-36.7 years. Two studies compared UST and anti-TNF, one study compared UST and no biologic, one study compared UST and vedolizumab, and one study compared UST, anti-TNF, vedolizumab and no biologic to each other for rates of intra-abdominal sepsis. Patients received UST within 12 weeks of surgery in 4 studies, and within 16 weeks in one study. The follow-up period was 30 days in 3 studies, up to 6 months in one, and 90 days in one study. Among patients with UST exposure, $36.4 \%$ of patients were on preoperative steroids and $18.8 \%$ were smokers. The surgical procedure ranged from total abdominal colectomy to strictureplasty, depending on the individual patient and operating surgeon. A majority (63.8\%) of patients had ostomy creation and only $39.4 \%$ had laparoscopic procedures. The baseline and operative characteristics are described in Table 1.

\section{Characteristics and quality of included studies}

All the included studies were retrospective in nature. Three studies were multicenter and the other 2 were single-center studies. Based on the Newcastle-Ottawa scale, all studies were of high quality.

\section{Meta-analysis outcomes}

A total of 189 patients exposed to UST preoperatively were included in the analysis from 5 studies. Data on assessed outcomes are described in Table 2.

There were 3 studies reporting adverse events in the UST group. The pooled rate of any postoperative complication was $23.5 \%$ (95\%CI 16-33.1), $I^{2}=0 \%$ (95\%CI 0-34.4) (Fig. 2A). The pooled rate of any infectious complications was $20.2 \%$ (95\%CI 
Table 2 Data on assessed outcomes of each study included in the analysis

\begin{tabular}{|c|c|c|c|c|c|c|c|c|c|c|}
\hline $\begin{array}{l}\text { Author } \\
\text { [Ref.] }\end{array}$ & Year & $\begin{array}{l}\text { Last } \\
\text { dose of } \\
\text { drug }\end{array}$ & $\begin{array}{l}\text { Follow } \\
\text { up }\end{array}$ & Group & Number & $\begin{array}{l}\text { Overall any } \\
\text { complication }\end{array}$ & $\begin{array}{c}\text { Any } \\
\text { infectious } \\
\text { complication } \\
\text { including SSI }\end{array}$ & $\begin{array}{l}\text { Intra- } \\
\text { abdominal } \\
\text { sepsis }\end{array}$ & Readmission & Reoperation \\
\hline \multirow{2}{*}{$\begin{array}{l}\text { Lightner } \\
\text { et al } 1 \\
{[29]}\end{array}$} & \multirow[t]{2}{*}{2018} & \multirow[t]{2}{*}{12 weeks } & \multirow[t]{2}{*}{30 days } & UST & 44 & 10 & 6 & 2 & 8 & 7 \\
\hline & & & & $\begin{array}{l}\text { Anti- } \\
\text { TNF }\end{array}$ & 169 & 57 & 42 & 22 & 17 & 7 \\
\hline \multirow{2}{*}{$\begin{array}{l}\text { Novello } \\
\text { et al [30] }\end{array}$} & \multirow[t]{2}{*}{2018} & \multirow[t]{2}{*}{12 weeks } & \multirow[t]{2}{*}{30 days } & UST & 30 & 8 & 7 & NR & 2 & 0 \\
\hline & & & & Vedo & 73 & 40 & 11 & NR & 10 & 4 \\
\hline \multirow{4}{*}{$\begin{array}{l}\text { Lightner } \\
\text { et al } 3 \\
{[28]}\end{array}$} & \multirow[t]{4}{*}{2019} & \multirow[t]{4}{*}{12 weeks } & \multirow[t]{4}{*}{30 days } & UST & 38 & NR & NR & 2 & NR & NR \\
\hline & & & & $\begin{array}{l}\text { Anti- } \\
\text { TNF }\end{array}$ & 272 & NR & NR & 16 & NR & NR \\
\hline & & & & Vedo & 127 & NR & NR & 7 & NR & NR \\
\hline & & & & NB & 275 & NR & NR & 0 & NR & NR \\
\hline \multirow{2}{*}{$\begin{array}{l}\text { Shimm } \\
\text { et al [18] }\end{array}$} & \multirow[t]{2}{*}{2018} & \multirow{2}{*}{$\begin{array}{l}4 \\
\text { months }\end{array}$} & \multirow{2}{*}{$\begin{array}{l}\text { Up to } 6 \\
\text { months }\end{array}$} & UST & 20 & 4 & 1 & 0 & 2 & 2 \\
\hline & & & & $\begin{array}{l}\text { Anti- } \\
\text { TNF }\end{array}$ & 40 & 23 & 14 & 9 & 6 & 6 \\
\hline \multirow{2}{*}{$\begin{array}{l}\text { Lightner } \\
\text { et al } 2 \\
{[16]}\end{array}$} & \multirow[t]{2}{*}{2018} & \multirow[t]{2}{*}{12 weeks } & \multirow[t]{2}{*}{90 days } & UST & 57 & NR & 20 & 8 & 20 & 10 \\
\hline & & & & NB & 277 & NR & 61 & 14 & 50 & 25 \\
\hline
\end{tabular}

UST, ustekinumab; TNF, tumor necrosis factor; Vedo, vedolizumab; NB, no biologic; SSI, surgical site infection; NR, not reported

10.3-35.9), $I^{2}=67$ (95\%CI 5.1-88.8) from 4 studies (Fig. 2B). Because of the study variability and limited data, further subgrouping of infectious complications was not possible.

The pooled rate of intra-abdominal sepsis in UST group was $7.2 \%$ (95\%CI 3.0-16.4), $I^{2}=15$ (95\%CI 0-86.9) from 4 studies, whereas the pooled rate of intra-abdominal sepsis in the anti-TNF group was $11.9 \%$ (95\%CI 5.9-22.5), $I^{2}=71$ (95\%CI 53.3-94.8) from 3 studies (Fig. 3). There was no significant difference between the 2 groups $(P=0.4)$. We also performed a second analysis including 3 studies that directly compared UST and anti-TNF. The odds ratio of intraabdominal sepsis comparing preoperative UST use to antiTNF use was 0.41 (95\%CI $0.12-1.23), I^{2}=14$ (95\%CI 0-91; $P=0.11$ ) (Supplementary Fig. 1).

The pooled rate of readmission and reoperation in the UST group was $17.4 \%$ (95\%CI 7.9-34), $I^{2}=72$ (95\%CI 20-90) (Fig. 4A) and 14.6\% (95\%CI 9-22.7), $I^{2}=12$ (95\%CI 0-86.8), (Fig. 4B) respectively, from 4 studies.

\section{Meta-regression}

Meta-regression was performed for any adverse outcomes, infectious complications, intra-abdominal sepsis and reoperation. The variables included were preoperative steroid use and stoma creation. Preoperative steroid use and ostomy creation were not significant predictors for any of the outcomes. The results of meta-regression with their coefficient and 95\%CI are summarized in Supplementary Table 3.

\section{Validation of meta-analysis results}

\section{Sensitivity analysis}

Sensitivity analysis was performed by excluding one study at a time and analyzing its effect on the main summary estimate. On this analysis, no single study significantly affected the outcome or the heterogeneity.

To assess for potential data duplication from overlapping authors or institution(s), we contacted the study authors and determined that there was patient overlap in 3 studies included in the meta-analysis, but differences in outcomes were reported. One study [30] had only rates of intra-abdominal sepsis whereas another $2[16,29]$ contributed to other outcomes. When the first overlapping study was excluded [29], the rates of infectious complications, readmissions and reoperations were $23.4 \%$ (95\%CI 10.9-43.2), $15.6 \%$ (95\%CI 4.2-43.4) and $11.4 \%$ (95\%CI $4.3-26.9$ ), respectively, and when the second overlapping study was excluded [16], the respective rates were $15.6 \%$ (95\%CI 8.0-28.0), $13.5 \%$ (95\%CI 7.5-23.1) and $10.9 \%$ (95\%CI 4.5-24.6). There were no studies with overlap in the outcomes regarding overall complications.

\section{Heterogeneity}

We assessed the dispersion of the calculated rates using the $I^{2}$ percentage values. The calculated $I^{2}$ values are reported with the pooled results. There was low heterogeneity 


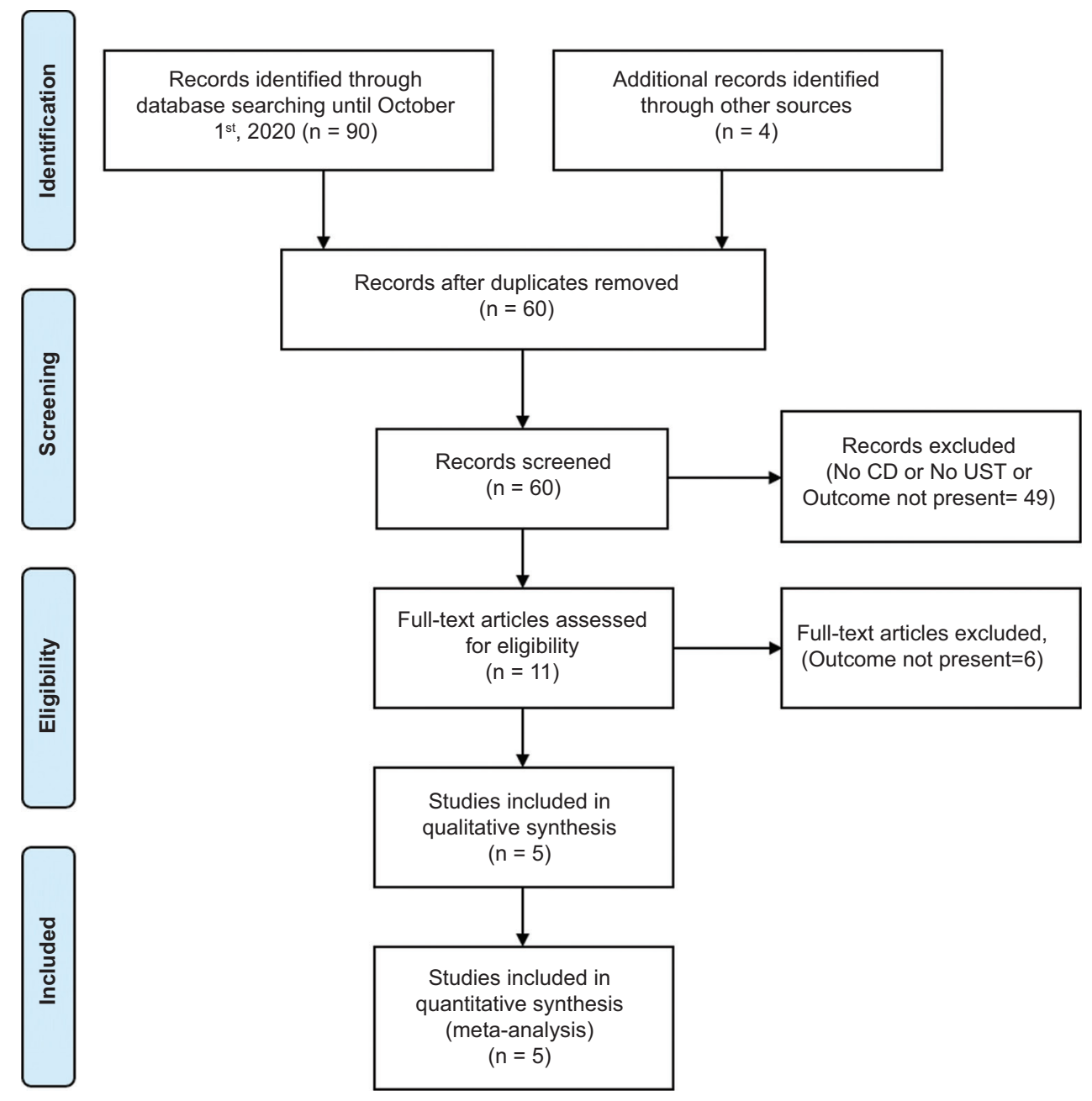

Figure 1 PRISMA flow diagram showing search strategy for meta-analysis CD, Crohn's disease; UST, ustekinumab

in overall complication, intra-abdominal sepsis and reoperation outcomes; however, in view of the wide $95 \%$ CIs, high heterogeneity cannot be excluded. Heterogeneity was substantial in the infectious complications and readmissions outcomes. This was probably due to baseline patient characteristics, as we were unable to do a subgroup analysis of patients on steroids and other CD medications preoperatively. In addition, the number of procedures and types of surgery also contributed to heterogeneity in the study population. We also acknowledge that $I^{2}$ values have limited utility to detect heterogeneity when the number of studies is small.

\section{Publication bias}

Publication bias was not assessed as fewer than 10 studies were included in the analysis.

\section{Discussion}

Our study demonstrated that the surgical complication rate in patients with preoperative UST exposure is similar to that for anti-TNFs. Even though we were not able to directly compare UST with vedolizumab and other biologics, the reported rate of postoperative complications is comparable to that of other biologics, including vedolizumab. Preoperative exposure to ustekinumab does not seem to influence postoperative complication risk. Identifying risk factors for postoperative complications is of paramount importance to optimize surgical and disease-related outcomes. We are likely to see a higher number of patients with medically refractory disease who received UST preoperatively.

The current literature on postoperative complications and biologic use is controversial, limited by observational studies and significant heterogeneity. The reported rates of overall postoperative complications and infectious complications 


\begin{tabular}{|c|c|c|c|c|c|c|c|c|}
\hline \multirow[t]{2}{*}{$\mathrm{A}_{\text {Study name }}$} & \multirow[b]{2}{*}{$\begin{array}{l}\text { Event } \\
\text { rate }\end{array}$} & \multicolumn{2}{|c|}{ Statistics for each study } & \multicolumn{5}{|c|}{ Event rate and $95 \% \mathrm{Cl}$} \\
\hline & & $\begin{array}{c}\text { Lower } \\
\text { limit }\end{array}$ & $\begin{array}{c}\text { Upper } \\
\text { limit }\end{array}$ & & & & & \\
\hline Lightner[1] & 0.227 & 0.127 & 0.373 & & & & & \\
\hline Novello & 0.267 & 0.139 & 0.450 & & & & & \\
\hline Shimm & 0.200 & 0.077 & 0.428 & & & & & \\
\hline & 0.235 & 0.160 & 0.331 & & & & & \\
\hline & & & & -1.00 & -0.50 & 0.00 & 0.50 & 1.00 \\
\hline \multicolumn{9}{|l|}{ B } \\
\hline \multirow[t]{2}{*}{ Study name } & \multicolumn{3}{|c|}{ Statistics for each study } & \multicolumn{5}{|c|}{ Event rate and $95 \% \mathrm{Cl}$} \\
\hline & $\begin{array}{c}\text { Event } \\
\text { rate }\end{array}$ & $\begin{array}{l}\text { Lower } \\
\text { limit }\end{array}$ & $\begin{array}{c}\text { Upper } \\
\text { limit }\end{array}$ & & 口 & & & \\
\hline Lightner[1] & 0.136 & 0.063 & 0.272 & & & & & | \\
\hline Novello & 0.233 & 0.116 & 0.415 & & & & & \\
\hline Shimm & 0.050 & 0.007 & 0.282 & & & & & \\
\hline \multirow[t]{3}{*}{ Lightner[2] } & 0.351 & 0.239 & 0.482 & & & & & \\
\hline & 0.251 & 0.184 & 0.333 & & & & & \\
\hline & & & & -0.50 & -0.25 & 0.00 & 0.25 & 0.50 \\
\hline
\end{tabular}

Figure 2 Pooled rate of any postoperative complication (a) and any infectious complication (b) in patients with preoperative ustekinumab use CI, confidence interval

\begin{tabular}{|c|c|c|c|c|c|c|c|}
\hline \multirow{2}{*}{$\frac{\text { Group by }}{\text { Treatment }}$} & \multirow[t]{2}{*}{ Study name } & & \multicolumn{2}{|c|}{ Statistics for each study } & \multicolumn{3}{|c|}{ Event rate and $95 \% \mathrm{Cl}$} \\
\hline & & $\begin{array}{l}\text { Event } \\
\text { rate }\end{array}$ & $\begin{array}{l}\text { Lower } \\
\text { limit }\end{array}$ & $\begin{array}{l}\text { Upper } \\
\text { limit }\end{array}$ & & & \\
\hline anto-TNF & Lightner[1] & 0.130 & 0.087 & 0.190 & & & \\
\hline anb-TNF & Lightner[3] & 0.059 & 0.036 & 0.094 & & & \\
\hline anti-TNF & Shimm & 0.225 & 0.121 & 0.379 & & & \\
\hline anti-TNF & & 0.119 & 0.059 & 0.225 & & & \\
\hline UST & Lightner[1] & 0.045 & 0.011 & 0.164 & & & \\
\hline UST & Lightner[3] & 0.053 & 0.013 & 0.187 & & & \\
\hline UST & Shinnm & 0.024 & 0.001 & 0.287 & & & \\
\hline UST & Lightner[2] & 0.140 & 0.072 & 0.256 & & & \\
\hline \multirow[t]{2}{*}{ UST } & & 0.072 & 0.030 & 0.164 & & & \\
\hline & & & & -1.00 & -0.50 & 0.00 & 1.00 \\
\hline
\end{tabular}

Figure 3 Pooled rate of postoperative intra-abdominal sepsis in patients who received preoperative anti- TNF and UST

TNF, tumor necrosis factor; UST, ustekinumab; CI, confidence interval

after preoperative anti-TNF exposure are $42.3 \%$ and $27.2 \%$, respectively, and the respective rates after preoperative vedolizumab exposure are $30.4 \%$ and $22.4 \%$ [15,32]. Based on our study, we reported that preoperative UST exposure was associated with similar rates of any adverse event $(23.5 \%, 95 \% \mathrm{CI}$ 16-33.1), and any infectious complications (20.2\%, 95\%CI 10.335.9). Two systematic reviews did not find any significant risk of postoperative infection and complications in patients exposed to vedolizumab preoperatively, compared to anti-TNF and no biologic therapy $[15,32]$. On the other hand, the data on antiTNF are much more conflicting, with some studies reporting higher rates of postoperative complications and others reporting no difference compared to no biologic therapy [12,33-36].

While the current study could only make limited comparator assessments, overall, the data on preoperative UST exposure in $\mathrm{CD}$ are reassuring. One study reported a higher rate of intra-abdominal sepsis in UST exposed patient compared to no biologic therapy [16]. In that study, there was significantly more use of preoperative immunomodulators in the UST group, while a greater number of patients underwent laparoscopic procedures and primary anastomoses in the no biologic group, which may have confounded the results. These results were not consistent in a large multicenter study that compared preoperative no biologic, anti-TNF, vedolizumab and UST exposure and did not report an increased risk of intra-abdominal sepsis in the UST-exposed group. On multivariate analysis, preoperative steroid use and combination immunosuppression with steroids remained an independent predictor of intra-abdominal sepsis, suggesting steroids as a likely confounding agent [29,37]. Similarly, Novello et al.., in a case-matched analysis, did not find a higher risk of postoperative complications (any postoperative complications, infectious complications, readmission and 


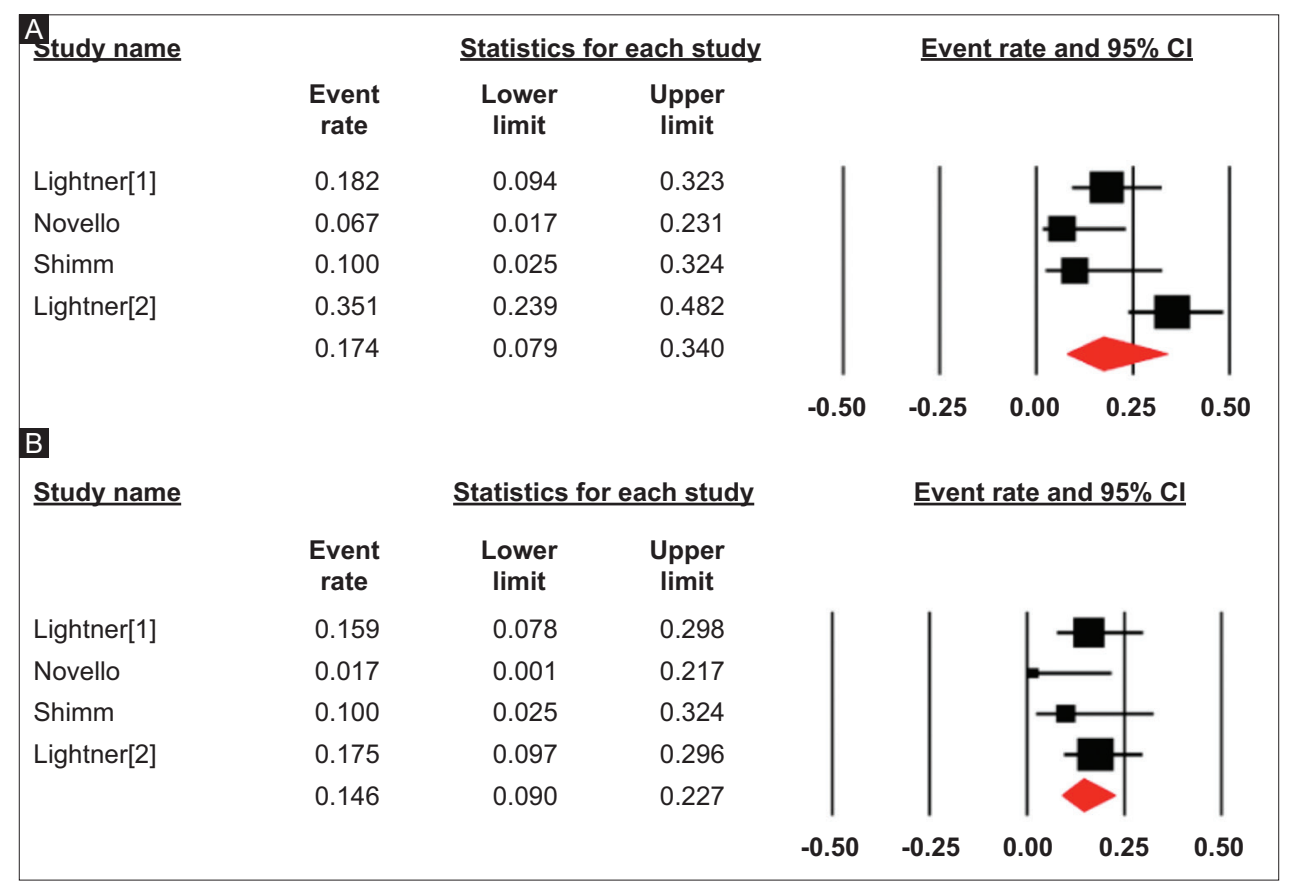

Figure 4 Pooled rates of readmission (A) and reoperation (B) in patients with preoperative ustekinumab use CI, confidence interval

reoperation) in the UST group as compared to preoperative vedolizumab use [31]. Another multicenter study from Canada also did not show any higher risk of postoperative complications in patients who received UST, compared to preoperative antiTNF use [18]. A similar trend is seen for vedolizumab, with earlier studies reporting a higher risk of adverse events and later studies with larger sample size reporting no greater risk of postoperative complications after preoperative vedolizumab use $[13,15]$. Taken together, these studies suggest the relative safety of UST in a perioperative setting.

The limitations of this study include the fact that it evaluated only small, tertiary-care referral center studies, potentially restricting the generalizability of the results. Studies were retrospective in nature, potentially contributing to selection bias and confounding. The time period of preoperative UST administration was not consistent throughout the study period. In addition, there was no standardization of the surgical procedure in the studies evaluated. UST patients were more likely to undergo ostomy creation rather than primary anastomosis, given their severe disease and complex phenotype. Small sample sizes and studies with overlapping cohorts further contributed to the low power and low impact of meta-regression results in our study. Because of limited data availability, further analysis with subgroups, such as the number of surgeries already performed, was not possible. Data limitations also did not allow for adequate assessment of confounders, comparator populations, or additional subgroup analysis. We also could not control for other factors such as nutrition, disease severity, prior biologic use, and type of surgery.

The strengths of this review include the systematic literature search with well-defined inclusion criteria, careful exclusion of redundant studies, inclusion of good quality studies, detailed extraction of data and rigorous evaluation of study quality. This is the first meta-analysis reporting the effect of preoperative UST use on postoperative complications in CD.

In conclusion, our meta-analysis demonstrates that the rate of postoperative complications in UST-exposed CD surgical patients may be similar to that of other biologics. Together, perioperative biologics may appear safe. Future prospective studies are needed to validate these findings and determine their influence on surgical decision-making.

\section{Summary Box}

\section{What is already known:}

- Current data on the risk of postoperative complications in patients receiving ustekinumab for Crohn's disease undergoing surgery are conflicting

\section{What the new findings are:}

- In a meta-analysis of 189 patients exposed to ustekinumab preoperatively, the surgical complication rate was similar to that of anti-tumor necrosis factor

- The reported rate of postoperative complications after preoperative ustekinumab exposure may be comparable to other biologics, including vedolizumab 


\section{References}

1. Abraham C, Cho JH. Inflammatory bowel disease. $N$ Engl J Med 2009;361:2066-2078.

2. Baumgart DC, Sandborn WJ. Crohn's disease. Lancet 2012;380:1590-1605.

3. Adegbola SO, Sahnan K, Warusavitarne J, Hart A, Tozer P. AntiTNF therapy in Crohn's disease. Int J Molec Sci 2018;19:2244.

4. Akobeng AK, Zachos M. Tumor necrosis factor-alpha antibody for induction of remission in Crohn's disease. Cochrane Database Syst Rev 2004;(1):CD003574.

5. Colombel JF, Sands BE, Rutgeerts P, et al. The safety of vedolizumab for ulcerative colitis and Crohn's disease. Gut 2017;66:839-851.

6. Deepak P, Sandborn WJ. Ustekinumab and anti-interleukin-23 agents in Crohn's disease. Gastroenterol Clin North Am 2017;46:603-626.

7. Feagan BG, Sandborn WJ, Gasink C, et al.; UNITI-IM-UNITI Study Group. Ustekinumab as induction and maintenance therapy for Crohn's disease. N Engl J Med 2016;375:1946-1960.

8. Khanna R, Mosli MH, Feagan BG. Anti-integrins in ulcerative colitis and Crohn's disease: what is their place? Dig Dis 2016;34:153-159.

9. Peyrin-Biroulet L, Oussalah A, Williet N, Pillot C, Bresler L, Bigard MA. Impact of azathioprine and tumour necrosis factor antagonists on the need for surgery in newly diagnosed Crohn's disease. Gut 2011;60:930-936.

10. Holubar SD, Dozois EJ, Privitera A, Pemberton JH, Cima RR, Larson DW. Minimally invasive colectomy for Crohn's colitis: a single institution experience. Inflamm Bowel Dis 2010;16:1940-1946.

11. Lau C, Dubinsky M, Melmed G, et al. The impact of preoperative serum anti-TNF $\alpha$ therapy levels on early postoperative outcomes in inflammatory bowel disease surgery. Ann Surg 2015;261:487-496.

12. Narula N, Charleton D, Marshall JK. Meta-analysis: peri-operative anti-TNF $\alpha$ treatment and post-operative complications in patients with inflammatory bowel disease. Aliment Pharmacol Ther 2013;37:1057-1064.

13. Lightner AL, Raffals LE, Mathis KL, et al. Postoperative outcomes in vedolizumab-treated patients undergoing abdominal operations for inflammatory bowel disease. J Crohns Colitis 2017;11:185-190.

14. Yamada A, Komaki Y, Patel N, et al. Risk of postoperative complications among inflammatory bowel disease patients treated preoperatively with vedolizumab. Am J Gastroenterol 2017;112:1423-1429.

15. Yung DE, Horesh N, Lightner AL, et al. Systematic review and meta-analysis: vedolizumab and postoperative complications in inflammatory bowel disease. Inflamm Bowel Dis 2018;24:2327-2338.

16. Lightner A, Grass F, Alsughayer A, Petersen M, Raffals L, Loftus E. Postoperative outcomes in ustekinumab-treated patients undergoing abdominal operations for Crohn's disease: singlecenter series. Crohns Colitis 360 2019;1:otz018. doi: 10.1093/ $\mathrm{crocol} /$ otz018

17. Shim HH, Ma C, Kotze PG, Panaccione R. Pre-operative exposure to ustekinumab: a risk factor for postoperative complications in Crohn's disease (CD)? Curr Drug Targets 2019;20:1369-1372.

18. Shim HH, Ma C, Kotze PG, et al. Preoperative ustekinumab treatment is not associated with increased postoperative complications in Crohn's disease: a Canadian multi-centre observational cohort study. J Can Assoc Gastroenterol 2018;1:115-123.

19. Moher D, Liberati A, Tetzlaff J, Altman DG; PRISMA Group. Preferred reporting items for systematic reviews and meta- analyses: the PRISMA statement. Ann Intern Med 2009;151:264269, W64.

20. Stroup DF, Berlin JA, Morton SC, et al. Meta-analysis of observational studies in epidemiology: a proposal for reporting. Meta-analysis Of Observational Studies in Epidemiology (MOOSE) group. JAMA 2000;283:2008-2012.

21. Stang A. Critical evaluation of the Newcastle-Ottawa scale for the assessment of the quality of nonrandomized studies in metaanalyses. Eur J Epidemiol 2010;25:603-605.

22. DerSimonian R, Laird N. Meta-analysis in clinical trials. Control Clin Trials 1986;7:177-188.

23. Sutton AJ, Abrams KR, Jones DR, et al. Methods for meta-analysis in medical research. John Wiley and Sons Ltd.: New York; 2000, pp. 205-228.

24. Kanwal F, White D. "Systematic reviews and meta-analyses" in Clinical Gastroenterology and Hepatology. Clin Gastroenterol Hepatol 2012;10:1184-1186.

25. Higgins JP, Thompson SG, Deeks JJ, Altman DG. Measuring inconsistency in meta-analyses. BMJ 2003;327:557-560.

26. Mohan BP, Adler DG. Heterogeneity in systematic review and meta-analysis: how to read between the numbers. Gastrointest Endosc 2019;89:902-903.

27. Guyatt GH, Oxman AD, Kunz R, et al. GRADE guidelines: 7. Rating the quality of evidence-inconsistency. J Clin Epidemiol 2011;64:1294-1302.

28. Easterbrook PJ, Berlin JA, Gopalan R, Matthews DR. Publication bias in clinical research. Lancet 1991;337:867-872.

29. Lightner AL, McKenna NP, Alsughayer A, et al. Biologics and 30day postoperative complications after abdominal operations for Crohn's disease: are there differences in the safety profiles? Dis Colon Rectum 2019;62:1352-1362.

30. Lightner AL, McKenna NP, Tse CS, et al. Postoperative outcomes in ustekinumab-treated patients undergoing abdominal operations for Crohn's disease. J Crohns Colitis 2018;12:402-407.

31. Novello M, Stocchi L, Holubar S, et al. Surgical outcomes of patients treated with ustekinumab vs. vedolizumab in inflammatory bowel disease: a matched case analysis. Int J Colorectal Dis 2019;34:451-457.

32. Law CCY, Narula A, Lightner AL, McKenna NP, Colombel JF, Narula N. Systematic review and meta-analysis: preoperative vedolizumab treatment and postoperative complications in patients with inflammatory bowel disease. J Crohns Colitis 2018;12:538-545.

33. Kopylov U, Ben-Horin S, Zmora O, Eliakim R, Katz LH. Antitumor necrosis factor and postoperative complications in Crohn's disease: systematic review and meta-analysis. Inflamm Bowel Dis 2012;18:2404-2413.

34. Fumery M, Seksik P, Auzolle C, et al.; REMIND study group investigators. Postoperative complications after ileocecal resection in Crohn's disease: a prospective study from the REMIND group. Am J Gastroenterol 2017;112:337-345.

35. Kotze PG, Saab MP, Saab B, et al. Tumor necrosis factor alpha inhibitors did not influence postoperative morbidity after elective surgical resections in Crohn's disease. Dig Dis Sci 2017;62:456-464.

36. Rosenfeld G, Qian H, Bressler B. The risks of post-operative complications following pre-operative infliximab therapy for Crohn's disease in patients undergoing abdominal surgery: a systematic review and meta-analysis. J Crohns Colitis 2013;7:868-877.

37. Nguyen GC, Elnahas A, Jackson TD. The impact of preoperative steroid use on short-term outcomes following surgery for inflammatory bowel disease. J Crohns Colitis 2014;8:1661-1667. 


\section{Supplementary material}

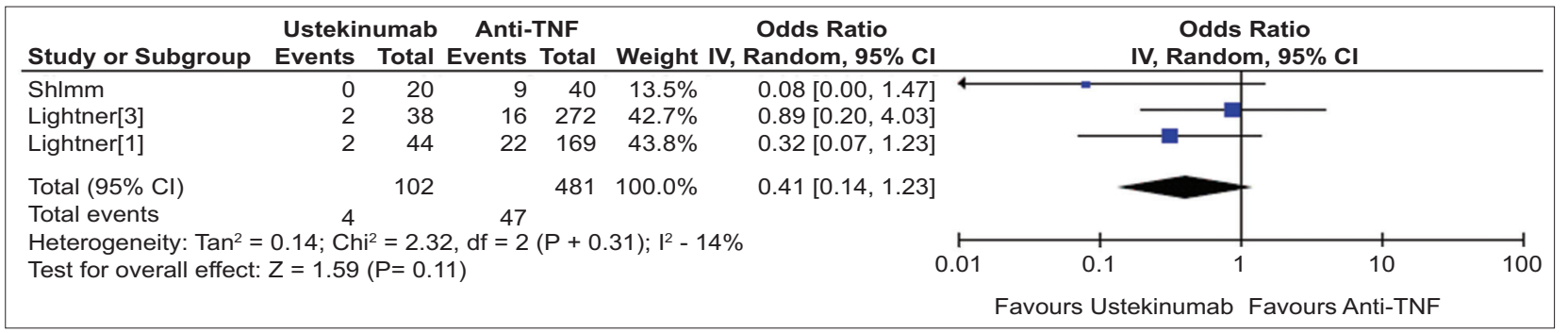

Supplementary Figure 1 Forest plot showing odds ratio of intra-abdominal sepsis comparing preoperative ustekinumab and anti-TNF CI, confidence interval; TNF, tumor necrosis factor

\begin{tabular}{|c|c|c|}
\hline $\begin{array}{l}\text { Item } \\
\text { No }\end{array}$ & Recommendation & $\begin{array}{l}\text { Reported } \\
\text { on page No }\end{array}$ \\
\hline \multicolumn{3}{|c|}{ Reporting of background should include } \\
\hline 1 & Problem definition & 5 \\
\hline 2 & Hypothesis statement & - \\
\hline 3 & Description of study outcome(s) & 7 \\
\hline 4 & Type of exposure or intervention used & $5-6$ \\
\hline 5 & Type of study designs used & $5-6$ \\
\hline 6 & Study population & 6 \\
\hline \multicolumn{3}{|c|}{ Reporting of search strategy should include } \\
\hline 7 & $\begin{array}{l}\text { Qualifications of searchers (e.g., librarians } \\
\text { and investigators) }\end{array}$ & 6 , Title page \\
\hline 8 & $\begin{array}{l}\text { Search strategy, including time period } \\
\text { included in the synthesis and key words }\end{array}$ & 6 , Table 1 \\
\hline 9 & $\begin{array}{l}\text { Effort to include all available studies, } \\
\text { including contact with authors }\end{array}$ & 6 \\
\hline 10 & Databases and registries searched & 6 \\
\hline 11 & $\begin{array}{l}\text { Search software used, name and version, } \\
\text { including special features used (e.g., } \\
\text { explosion) }\end{array}$ & 6 \\
\hline 12 & $\begin{array}{l}\text { Use of hand searching (e.g., reference lists } \\
\text { of obtained articles) }\end{array}$ & 6 \\
\hline 13 & $\begin{array}{l}\text { List of citations located and those excluded, } \\
\text { including justification }\end{array}$ & 8, Fig. 1 \\
\hline 14 & $\begin{array}{l}\text { Method of addressing articles published in } \\
\text { languages other than English }\end{array}$ & 6 \\
\hline 15 & $\begin{array}{l}\text { Method of handling abstracts and } \\
\text { unpublished studies }\end{array}$ & 6 \\
\hline 16 & Description of any contact with authors & 6 \\
\hline \multicolumn{3}{|c|}{ Reporting of methods should include } \\
\hline 17 & $\begin{array}{l}\text { Description of relevance or appropriateness } \\
\text { of studies assembled for assessing the } \\
\text { hypothesis to be tested }\end{array}$ & $6-7$ \\
\hline 18 & $\begin{array}{l}\text { Rationale for the selection and coding } \\
\text { of data (e.g., sound clinical principles or } \\
\text { convenience) }\end{array}$ & $6-7$ \\
\hline
\end{tabular}




$\begin{array}{lc}\text { Item Recommendation } & \text { Reported } \\ \text { No } & \text { on page No }\end{array}$

19 Documentation of how data were classified 6-7 and coded (e.g., multiple raters, blinding and interrater reliability)

20 Assessment of confounding (e.g., comparability of cases and controls in studies where appropriate)

21 Assessment of study quality, including blinding of quality assessors, stratification or regression on possible predictors of study results

22 Assessment of heterogeneity

23 Description of statistical methods (e.g., complete description of fixed or random effects models, justification of whether the chosen models account for predictors of study results, dose-response models, or cumulative meta-analysis) in sufficient detail to be replicated

24 Provision of appropriate tables and graphics

Reporting of results should include

25 Graphic summarizing individual study estimates and overall estimate

\begin{tabular}{|c|c|c|}
\hline 26 & $\begin{array}{l}\text { Table giving descriptive information for } \\
\text { each study included }\end{array}$ & Table 2 \\
\hline 27 & $\begin{array}{l}\text { Results of sensitivity testing (e.g., subgroup } \\
\text { analysis) }\end{array}$ & 9 \\
\hline 28 & Indication of statistical uncertainty of findings & $10-12$ \\
\hline \multicolumn{3}{|c|}{ Reporting of discussion should include } \\
\hline 29 & $\begin{array}{l}\text { Quantitative assessment of bias (e.g., } \\
\text { publication bias) }\end{array}$ & 10 \\
\hline 30 & $\begin{array}{l}\text { Justification for exclusion (e.g., exclusion of } \\
\text { non-English language citations) }\end{array}$ & 6 \\
\hline 31 & Assessment of quality of included studies & $8-9$ \\
\hline \multicolumn{3}{|c|}{ Reporting of conclusions should include } \\
\hline 32 & $\begin{array}{l}\text { Consideration of alternative explanations } \\
\text { for observed results }\end{array}$ & $10-12$ \\
\hline 33 & $\begin{array}{l}\text { Generalization of the conclusions (i.e., } \\
\text { appropriate for the data presented and } \\
\text { within the domain of the literature review) }\end{array}$ & 12 \\
\hline & Guidelines for future research & 12 \\
\hline & Disclosure of funding source & 1 \\
\hline
\end{tabular}

From: Stroup DF, Berlin JA, Morton SC, et al, for the meta-analysis of observational studies in epidemiology (MOOSE) Group. Meta-analysis of observational studies in epidemiology. A proposal for reporting. JAMA 2000;283:2008-2012. 